\title{
SELEÇÃo DE FAMÍLIAS DE FEIJOEIRO BASEADA NA PRODUTIVIDADE, NO TIPO DE GRÃOS E INFORMAÇÕES DE QTLS
}

\author{
Selection of common bean families based on grain type and yield, \\ and QTLs information
}

\author{
Paula Pereira Torga ${ }^{1}$, João Bosco dos Santos², Helton Santos Pereira ${ }^{3}$, \\ Daniel Furtado Ferreira ${ }^{4}$, Monik Evelin Leite ${ }^{5}$
}

\begin{abstract}
RESUMO
Objetivou-se neste trabalho, selecionar famílias de feijoeiro promissoras para a produtividade de grãos com tipo de grãos ideal utilizando informações fenotípicas e de marcadores moleculares ligados a QTLs. Foram utilizadas 100 famílias $F_{3: 7}$, avaliadas em três safras, com dois experimentos/safra, totalizando seis experimentos. A primeira safra foi a da seca/2007, na qual conduziu-se um experimento em Lavras-MG e o outro em Ijaci-MG. Nas safras de inverno/2007 e águas 2007/2008, foram conduzidos, em cada uma, um experimento em Lavras-MG e outro em Lambari-MG. Em todos eles foi utilizado o delineamento látice triplo 10x10, com parcelas de duas linhas de dois metros. As famílias foram avaliadas pela sua produtividade de grãos. Em apenas um dos experimentos de cada safra foi avaliado o tipo de grão. Os dados foram submetidos à análise de variância individual e conjunta, por local e por safra. 480 marcadores microssatélites foram testados para identificar polimorfismo entre os genitores. Os oito marcadores polimórficos identificados foram utilizados para a genotipagem das famílias. Entre esses, cinco explicaram parte da variação da produtividade de grãos. Os marcadores explicaram pequena porcentagem da variação fenotípica e apresentaram alta interação QTLs x ambientes. O ganho com a seleção fenotípica para produtividade de grãos foi de 7,4\%, e de 9,6\% para tipo de grãos, adotando a intensidade de seleção de 5\%. A seleção assistida por marcadores foi equivalente à fenotípica para produtividade de grãos, porque apenas um marcador mais estável contribuiu para a seleção com base na média dos ambientes.
\end{abstract}

Termos para indexação: Phaseolus vulgaris, linhagens,seleção assistida por marcadores, seleção fenotípica, microssatélites.

\section{ABSTRACT}

The objectives of this research were to select com mon bean families with high grain yield and ideal grain type using phenotypical information and molecular markers linked to the QTLs. One hundred $\mathrm{F}_{3: 7}$ families were evaluated in three seasons, in two field experiments per season. Two experiments were set up in the counties of Lavras and Ijaci in the dry season/2007, other four experiments were set up in Lavras and Lambari, two in the winter season/2007 and two in the 2007/2008 rainy season. A 10x10 lattice design was used in all experiments, using $2 \mathrm{~m}$-long plots and rows $50 \mathrm{~cm}$ apart. The families were evaluated based on grain yield in all experiments, and based on grain type in one experiment per season. Moreover, 480 microsatellite markers were tested in the parents. Eight markers were polymorphic and used for genotyping the families. Among them five explained part of the grain yield variability and presented high interaction by environments. Selecting $5 \%$ of the families the genetic gain was of 7,4\% for grain yield and $9,6 \%$ for grain type. The marker-assisted selection gave a similar result to the phenotypic selection because only one more stable marker of the along with average grain yield was used in the selection.

Index terms: Phaseolus vulgaris, lines, marker assisted selection, phenotypic selection, microsatellite.

(Recebido em 28 de agosto de 2008 e aprovado em 19 de março de 2009)

\section{INTRODUÇÃO}

O cultivo do feijoeiro na maioria das regiões produtoras do Brasil é realizado, predominantemente, com cultivares de grão tipo carioca. Estima-se que anualmente sejam cultivados mais de 2 milhões de hectares com feijões com esse tipo de grão (Embrapa, 2008). Por essa razão, nos programas de melhoramento de feijoeiro comum, grande atenção é dada à seleção de famílias segregantes com grão tipo carioca, que darão origem às novas linhagens e cultivares.

O aumento de produtividade das espécies cultivadas mais importantes tem sido o principal

\footnotetext{
1Universidade Federal de Goiás, Campus Samambaia - 74001-970 - Goiânia, GO - paulaptorga@yahoo.com.br

'Universidade Federal de Lavras - Departamento de Biologia - Lavras, MG

${ }^{3}$ Embrapa Arroz e Feijão - Santo Antônio de Goiás, GO

${ }^{4}$ Universidade Federal de Lavras - Departamento de Ciências Exatas - Lavras, MG

${ }^{5}$ Universidade Federal de Lavras - Departamento de Biologia - Lavras, MG
} 
responsável por atender à demanda crescente de alimentos e de outros produtos agrícolas, inclusive o feijão comum. Vários fatores contribuíram para esse aumento, com destaque para o melhoramento genético (Vencovsky \& Ramalho, 2000). A comprovada eficiência das técnicas clássicas de melhoramento resultou nos contínuos ganhos genéticos em produtividade obtidos ao longo de vários anos e para várias culturas (Atroch \& Nunes, 2000); para o feijão, estima-se que esses ganhos sejam de 1,6\% ao ano (Matos, 2005). No entanto, sempre que houver novas ferramentas para melhorar a eficiência dos programas de melhoramento, elas devem ser empregadas.

Os marcadores moleculares podem ser utilizados como uma ferramenta para auxiliar no processo seletivo e, em caracteres quantitativos, como a produtividade de grãos, em que a influência do ambiente é maior, espera-se maior contribuição desses marcadores, pelas dificuldades envolvidas no processo de seleção (Ferreira \& Grattapaglia, 1998). Diversos trabalhos têm sido realizados nesse sentido (Blair et al., 2006a), entretanto, a maioria utilizando populações desenvolvidas para gerar grande variabilidade, em detrimento da média populacional (Pereira et al., 2007). Para que os marcadores moleculares sejam realmente integrados na rotina dos programas de melhoramento eles devem ser utilizados em populações "elites", que aliem variabilidade e alta média populacional.

Objetivou-se neste trabalho, selecionar famílias de feijão carioca superiores em produtividade e tipo de grãos, e avaliar a contribuição de marcadores de QTLs de produtividade de grãos para auxiliar na seleção dessas famílias.

\section{MATERIAL E MÉTODOS}

Foram utilizadas 100 famílias $\mathrm{F}_{3: 7}$, obtidas por Pereira et al. (2007), a partir do cruzamento entre as linhagens MAI 18.13 e Z-9. A linhagem MAI 18.13 tem grão tipo carioca, hábito de crescimento tipo III e resistência a algumas raças de Pseudocercospora griseola. A linhagem Z-9 possui grão tipo carioca, hábito de crescimento tipo III e é resistente às raças 81 e 89 de Colletotrichum lindemuthianum (Pereira et al., 2007). As famílias desse cruzamento foram selecionadas porque os genitores apresentaram alta capacidade geral de combinação para produtividade de grãos, maior quantidade de marcadores polimórficos de QTLs para o caráter produtividade de grãos, grãos com padrão carioca e alta produtividade média. As famílias foram avaliadas em seis experimentos, utilizando o delineamento látice triplo 10x10, com parcelas de duas linhas de dois metros e espaçamento de $50 \mathrm{~cm}$ entre as linhas, sendo semeadas 15 sementes por metro linear. Em cada safra foram conduzidos experimentos em dois locais. Na safra da seca/2007 $\left(\mathrm{F}_{3: 7}\right)$, os locais foram Lavras (MG) e Ijaci (MG), nas safras de inverno/2007 $\left(\mathrm{F}_{3: 8}\right)$ e águas 2007/2008 $\left(\mathrm{F}_{3: 9}\right)$ os locais foram Lavras $(\mathrm{MG})$ e Lambari (MG). Foi utilizada adubação no plantio com 300kg/ ha de 8-28-16 $\left(\mathrm{N}, \mathrm{P}_{2} \mathrm{O}_{5}, \mathrm{~K}_{2} \mathrm{O}\right)$ e adubação de cobertura 20 dias após a emergência, com $150 \mathrm{~kg} / \mathrm{ha}$ de sulfato de amônio. Os demais tratos culturais foram os comuns à cultura do feijoeiro, incluindo irrigações complementares por aspersão quando necessário. A produtividade de grãos foi medida em g/parcela ${ }^{-1}$ e transformada para $\mathrm{kg} / \mathrm{ha}^{-1}$ em todos os experimentos. $\mathrm{O}$ caráter tipo de grão foi avaliado em um experimento de cada safra, por dois avaliadores, adotandose a escala descritiva de notas proposta por Marques Júnior (1997), sendo o valor 1 atribuído ao tipo de grão mais aceito pelo mercado e 5 ao grão fora do padrão.

Foram realizadas análises de variância por experimento utilizando o aplicativo MSTAT-C (1983) considerando o efeito do fator Famílias aleatório e o de Ambientes fixo. As análises conjuntas foram realizadas utilizando-se o programa SAS, versão 8.0, licenciado para o Departamento de Ciências Exatas da UFLA. A partir dessas análises, foram obtidas as esperanças dos quadrados médios conforme recomendações de Vencovsky \& Barriga (1992) e Ramalho et al. (2000), foram estimados os componentes de variância e parâmetros genéticos e fenotípicos, como herdabilidade e seus limites de confiança (Knapp et al., 1985) e o ganho esperado com a seleção, considerando $5 \%$ de intensidade de seleção (Ramalho et al., 1993), conforme a expressão :

$$
G S=d s \times h^{2}
$$

em que:

$d s$ : diferencial de seleção, ou seja, a diferença entre a média das famílias selecionadas e a média geral das famílias da população;

$h^{2}$ : herdabilidade do caráter na população.

Vale ressaltar que, ao avaliar linhas puras ou famílias com alto nível de endogamia, a variância genética entre as famílias é toda aditiva. Assim, quando se avaliam linhas puras, a herdabilidade estimada é equivalente àquela no sentido restrito.

Para as análises com marcadores moleculares microssatélites, visando identificar polimorfismo entre os genitores do cruzamento, foi realizada a extração de DNA dos genitores e das 100 plantas $\mathrm{F}_{3}$ que originaram as famílias e reações de PCR (Polimerase Chain Reaction) utilizando procedimentos descritos por Teixeira (2004), com 480 marcadores microssatélites, disponíveis em Bean Improvement Cooperative (2008). A genotipagem das 100 
famílias $\mathrm{F}_{3: 4}$ foi realizada com os oito marcadores que apresentaram polimorfismo entre os genitores (X74919; BM156; U77937; BMd-28; AZ301561.1; PVM03TC116; BM152; BMd-19).

Com esses resultados, foram realizadas análises de regressão linear simples e múltipla, com seleção de modelos pelo método de backward, para cada um dos oito marcadores, com os dados de produtividade de grãos, em cada experimento individualmente, por safra, por local e também para a análise envolvendo todos os experimentos (conjunta geral). As análises foram desenvolvidas utilizando-se o programa SAS, versão 8.0. A partir da análise de regressão linear múltipla backward, envolvendo todos os experimentos, foi obtido um único marcador estável, que foi utilizado para realizar a seleção assistida por marcadores (SAM). O estimador do índice (I) para a seleção assistida foi calculado pela expressão (Lande \& Thompson, 1990):

$$
I=b_{z} z+b_{m} m
$$

em que:

$b_{z}$ : herdabilidade do caráter produtividade de grãos; $z$ : produtividade média de grãos de cada família; $b_{m}$ : coeficiente de determinação do marcador; $m$ : código do genótipo marcador para cada família.

\section{RESULTADOS E DISCUSSÃO}

Os coeficientes de variação (CV) das análises individuais e conjunta para o caráter tipo de grãos foram relativamente baixos, variando de $10,56 \%$ a $19,75 \%$, o que indica boa precisão experimental. Observou-se a existência de diferenças genéticas significativas $(\mathrm{P}<0,01)$ entre as famílias em todas as safras e na análise conjunta, indicando a possibilidade de sucesso com a seleção para este caráter. A interação Ambientes x Famílias não foi significativa (Tabela 1), de modo semelhante ao relatado em outro trabalho (Silva, 2007), mostrando que o comportamento das famílias foi coincidente nos ambientes avaliados, e, portanto, não houve alteração no desempenho das mesmas.

As estimativas de herdabilidade variaram de $39 \%$ a $69 \%$, o que indica que o caráter tipo de grãos sofre, relativamente, pouca influência não controlável, ocorrendo, assim, uma situação favorável para realizar a seleção. Esses valores são considerados intermediários, sendo menores do que os relatados por Silva (2007), o que deve ter ocorrido em razão da menor variação genética da população, visto que os genitores possuem tipo de grãos próximo do ideal. Além disso, os intervalos de confiança da herdabilidade foram sempre positivos, indicando que os valores encontrados não são nulos, com $95 \%$ de confiança.

O ganho esperado com a seleção para o caráter tipo de grãos, estimado a partir da análise conjunta, foi de $-9,6 \%$ (Tabela 1), confirmando que esse caráter pode ser melhorado, obtendo-se ganhos expressivos. Vale ressaltar que o valor negativo obtido no ganho para esse caráter é vantajoso, uma vez que a menor nota é atribuída ao melhor tipo de grão. Como os genitores possuem tipos de grãos superiores, há a possibilidade de seleção de famílias com grandes chances de aceitação no mercado.

Em relação ao caráter produtividade de grãos, obteve-se boa precisão experimental, com CV's variando de $15,84 \%$, a $33,73 \%$. Na cultura do feijoeiro, além dos vários fatores experimentais, existem também os pós-colheita, como o manuseio das parcelas, que podem levar à menor precisão experimental (Souza et al., 2000). Assim, os valores

Tabela 1 - Resumo das análises conjuntas de variância, estimativas de herdabilidade $\left(\mathrm{h}^{2}\right)$ e de ganho com a seleção (GS) para os caracteres tipo de grãos e produtividade de grãos $\left(\mathrm{kg} \mathrm{ha}^{-1}\right)$, dos ensaios de feijoeiro comum tipo carioca em 2007.

\begin{tabular}{|c|c|c|c|c|}
\hline \multirow{2}{*}{ Fontes de variação } & \multicolumn{2}{|c|}{ Tipo de grãos } & \multicolumn{2}{|c|}{ Produtividade de grãos } \\
\hline & GL & QM & GL & QM \\
\hline Famílias & 99 & $0,111^{* *}$ & 99 & $1146088^{* * *}$ \\
\hline Ambientes & 2 & $1,082^{* *}$ & 5 & $57920034^{* *}$ \\
\hline Ambientes*famílias & 198 & $0,042^{\mathrm{ns}}$ & 495 & $699783^{* *}$ \\
\hline Erro & 298 & 0,115 & 1.026 & 356765 \\
\hline Média & \multicolumn{2}{|c|}{2,3} & \multicolumn{2}{|c|}{$2.413,2$} \\
\hline $\mathrm{CV}(\%)$ & \multicolumn{2}{|c|}{14,8} & \multicolumn{2}{|c|}{24,7} \\
\hline$h^{2}$ & \multicolumn{2}{|c|}{$62,2\left(47,3^{\mathrm{a}}-73,4^{\mathrm{b}}\right)$} & \multicolumn{2}{|c|}{$38,94\left(18,3^{\mathrm{a}}-55,8^{\mathrm{b}}\right)$} \\
\hline $\mathrm{GS}(\%)$ & \multicolumn{2}{|c|}{$-9,6$} & \multicolumn{2}{|c|}{7,4} \\
\hline
\end{tabular}

** Significativo, a $1 \%$ de probabilidade de erro, pelo teste de $\mathrm{F}$.

${ }^{\mathrm{a}, \mathrm{b}}$ Limite inferior (LI) e superior (LS) da herdabilidade, estimados a 5\% de probabilidade de erro. 
obtidos no presente trabalho estão de acordo com os relatados para a cultura (Marques Júnior, 1997). Em todas as análises individuais realizadas observaram-se diferenças significativas entre as famílias $(\mathrm{P}<0,05)$, indicando a existência de variabilidade genética entre as mesmas. Entretanto, a interação Famílias x Ambientes também foi significativa e, portanto, o comportamento das famílias não foi coincidente nos ambientes, certamente devido à alta sensibilidade dos genótipos às variações de ambiente para esse caráter (Tabela 1).

As estimativas de herdabilidade $\left(\mathrm{h}^{2}\right)$ para o caráter produtividade de grãos variaram de $(27,0 \%$ a $79,7 \%)$, sendo consideradas altas quando comparadas às normalmente relatadas para a cultura (Ramalho et al., 1993). Essa oscilação das estimativas pode ser explicada pela presença da interação das famílias com os ambientes. O ganho com a seleção foi de $7,4 \%$, demonstrando que, mesmo utilizando-se genitores já selecionados, há possibilidade de se obter sucesso com a seleção.

Considerando as cinco famílias selecionadas apenas pelo tipo de grão, o ganho indireto esperado para produtividade de grãos reduziu para $0,8 \%$. Quando se selecionou apenas para produtividade de grãos, o ganho indireto em tipo de grãos reduziu para -1,6\%. Isso acontece quando a variação dos dois caracteres ocorre em sentido não desejado. Como a correlação fenotípica entre as médias dos caracteres foi $-0,03$, não significativa, há a possibilidade de seleção de famílias com fenótipos ideais para os dois caracteres. Assim, para se obter famílias com chances de serem aceitas como cultivares, foi realizada a seleção com base em ambos os caracteres. Considerando a alta exigência dos consumidores por cultivares com padrão tipo carioca, de cor bege e apresentando listras, ambos o mais claro possível, optou-se por selecionar as cinco famílias mais produtivas entre as dez com melhor tipo de grãos. Nesse caso, os ganhos esperados com a seleção são de $-8,2 \%$ para tipo de grãos e de $1,6 \%$ para a produtividade de grãos.

As cinco famílias selecionadas apresentaram média de produtividade de $2.510 \mathrm{~kg} \mathrm{ha}^{-1}$ e continuarão no programa de melhoramento, sendo avaliadas nos ensaios de competição de linhagens, em mais ambientes, visando a identificação de linhagens com potencial para se tornar novas cultivares.

Entre os 480 microssatélites testados, somente oito foram polimórficos. Essa baixa taxa de polimorfismo pode ser explicada considerando-se que os genitores utilizados são linhagens "elites", selecionadas em programas anteriores e, portanto, a população gerada a partir desse cruzamento apresenta menor variabilidade. Além disso, o feijão é uma espécie na qual, naturalmente, não se encontra grande polimorfismo molecular, mesmo quando são utilizados genitores muito contrastantes (Blair et al., 2006b).

Os resultados das análises de regressão linear simples e regressão linear múltipla backward para o caráter produtividade de grãos encontram-se nas Tabelas 2 e 3, respectivamente. Os valores dos coeficientes de determinação $\left(\mathrm{R}^{2}\right)$ obtidos para os marcadores foram baixos, variando de $4,42 \%$ a $15,48 \%$, indicando que esses marcadores explicam uma parcela reduzida da variação fenotípica observada. Bernardo (2002) relatou que 72\% dos QTLs mapeados em diversos estudos para caracteres quantitativos, como produtividade de grãos, explicaram menos de $10 \%$ da variação fenotípica, corroborando com os resultados obtidos no presente trabalho.

Houve elevada interação dos QTLs com os ambientes, que ocorre quando há uma expressão diferencial dos QTLs em relação às mudanças ambientais ou quando há ausência de expressão do QTL em alguns dos ambientes avaliados (Santos, 2008). Essa interação pode ser verificada observando-se que, em alguns ambientes, como seca de 2007, inverno de 2007 e águas de 2007/2008, todos em Lavras (MG) e águas de 2007/2008 em Lambari (MG), não foi encontrado nenhum marcador explicando parte da variação para produtividade de grãos. A presença de interação QTLs por ambientes também pode ser observada pela variação nas estimativas de $\mathrm{R}^{2}$ para um mesmo marcador nas diferentes avaliações, como ocorreu para $\mathrm{o}$ marcador X74919, com valores de $\mathrm{R}^{2}$ variando de 0 a 9,99\%. As magnitudes e as instabilidades dos QTL detectados confirmam a dificuldade de identificar um marcador estável para a produtividade de grãos, assim como relatado em outros trabalhos (Melo et al., 2002; Teixeira et al., 2005; Santos, 2008).

A regressão múltipla para o caráter produtividade de grãos, com método de seleção de modelo backward (Tabela 3), indicou no modelo final da análise envolvendo todos os ambientes apenas o marcador BM-156, que foi utilizado na obtenção do índice para a realização da seleção assistida. As cinco famílias selecionadas com base na SAM foram as mesmas selecionadas com base no fenótipo somente para a produtividade de grãos, com média de $2.837 \mathrm{~kg} / \mathrm{ha}$. Entre essas, quatro apresentaram o genótipo marcador homozigoto para o alelo favorável. Assim, a utilização dos marcadores não apresentou vantagem sobre a seleção com base somente no caráter produtividade de grãos. Isso pode ser explicado pelo baixo número de marcadores polimórficos encontrados. Outra causa da baixa eficiência da SAM foi a pequena porcentagem da variação explicada pelo QTL, que pode 
Tabela 2 - Resumo das análises de regressão linear simples para o caráter produtividade de grãos de feijoeiro, considerando-se cada marcador separadamente nas análises individuais e conjuntas de cada safra.

\begin{tabular}{lcccc}
\hline Ambiente & Marcador & Pr $>\mathrm{F}$ & $\mathrm{R}^{2}(\%)^{1}$ & $\mathrm{~B}_{1}{ }^{2}$ \\
\hline \multirow{2}{*}{ Ijaci Seca/07 } & X74919 & 0,0018 & 9,99 & 174,64 \\
& BM-156 & 0,0085 & 7,22 & 156,42 \\
& AZ301561.1 & 0,0249 & 5,29 & 133,01 \\
\hline \multirow{2}{*}{ Conjunta Seca/07 } & X74919 & 0,0369 & 4,60 & 74,59 \\
& BM-156 & 0,0011 & 10,82 & 120,58 \\
\hline Lavras Inverno/07 & PVM03TC116 & 0,0030 & 9,05 & $-246,02$ \\
\hline Conjunta Lavras & PVM03TC116 & 0,0333 & 4,78 & $-131,95$ \\
\hline \multirow{2}{*}{ Conjunta geral } & BM-156 & 0,0089 & 7,12 & 84,27 \\
& U77937 & 0,0229 & 4,42 & 81,98 \\
\hline
\end{tabular}

${ }^{1}$ Coeficiente de determinação; ${ }^{2}$ Efeito de uma substituição alélica.

Tabela 3 - Resumo das análises de regressão linear múltipla com seleção de modelo pelo método "backward" para o caráter produtividade de grãos de feijoeiro nas análises individuais e conjuntas de cada safra.

\begin{tabular}{lcccc}
\hline Análise & Marcador & $\operatorname{Pr}>\mathrm{F}$ & $\mathrm{R}^{2}(\%)^{1}$ & $\mathrm{~B}_{1}{ }^{2}$ \\
\hline Ijaci Seca/07 & X74919 e BM-156 & 0,0002 & 15,48 & 175,32 e 157,27 \\
\hline Conjunta Seca/07 & X74919 e BM-156 & 0,0004 & 13,65 & 75,12 e 120,95 \\
\hline Conjunta geral & BM-156 & 0,0089 & 7,12 & 84,27 \\
\hline
\end{tabular}

${ }^{1}$ Coeficiente de determinação; ${ }^{2}$ Efeito de uma substituição alélica.

ter ocorrido devido à grande distância entre a marca e o QTL, ou pelo pequeno efeito do QTL na população utilizada, o que já havia sido relatado nos trabalhos de Rodrigues (2004) e Teixeira (2004).

O marcador BM156 foi identificado por esses autores e também no presente trabalho ligado ao QTL da produtividade de grãos. Como o marcador foi identificado no presente trabalho em mais de um ambiente (Tabelas 2 e 3) e utilizando uma população em geração mais avançada de autofecundação, quando o desequilíbrio de ligação tende a ser menor, há a possibilidade do marcador estar mais próximo do QTL. Vale ressaltar que entre as cinco famílias selecionadas com base na produtividade e tipo de grãos, quatro apresentaram o alelo favorável desse marcador.

\section{CONCLUSÕES}

Os marcadores de QTLs utilizados na SAM não contribuíram para selecionar famílias com maior produtividade na população em estudo.

Houve elevada interação QTLs x ambientes e genótipos $\mathrm{x}$ ambientes.

Foi possível selecionar famílias superiores tanto em produtividade quanto em tipo de grãos.

\section{REFERÊNCIAS BIBLIOGRÁFICAS}

ATROCH, A.L.; NUNES, G.H.S. Progresso genético em arroz de várzea úmida no estado do Amapá. Pesquisa Agropecuária Brasileira, Brasília, v.35, n.4, p.767-771, abr. 2000.

BEAN IMPROVEMENT COOPERATIVE. Genetics: bean SSR primers 2007. Disponível em: <http:// iwww.css.msu.edu/biơ Acesso em: 10 jul. 2008.

BERNARDO, R. Breeding for quantitative traits in plants. Minessota: Stema, 2002. 369p.

BLAIR, M.W.; GIRALDO, M.C.; BUENDÍA, H.F.; TOVAR, E.; DUQUE, M.C.; BEEBE, S.E. Microsatellite marker diversity in common bean (Phaseolus vulgaris L.). Theoretical and Applied Genetics, Berlin, v.113, p.100-109, 2006a.

BLAIR, M.W.; IRIARTE, G.; BEEBE, S. QTL analysis of yield in an advanced backcross population derived from a cultivated Andean x wild common bean (Phaseolus vulgaris $\mathrm{L}$.) cross. Theoretical and applied Genetics, Berlin, v.112, p.1149-1163, 2006 b. 
EMPRESA BRASILEIRA DE PESQUISA AGROPECUÁRIA. Arroz e feijão. Disponível em: WWw.cnpaf.embrapa.br/feijao/index.htm\#sistema>i. Acesso em: 10 jun. 2008.

FERREIRA, A.M.E.; GRATTAPAGLIA, D. Introdução ao uso de marcadores RAPD e RFLP em análise genética. 3.ed. Brasília: EMBRAPA-CENARGEN, 1998. 220p.

KNAPP, S.J.; STROUP, W.W.; ROSS, W.M. Exact confidence intervals for heritability on a progeny mean basis. Crop Science, Madison, v.25, n.1, p.192-194, Jan./ Feb. 1985.

LANDE, R.; THOMPSON, R. Efficiency of marker-assisted selection in the improvement of quantitative traits. Genetics, Baltimore, v.124, n.3, p.743-756, Mar. 1990.

MARQUES JÚNIOR, O.G. Eficiência de experimentos com a cultura do feijão. 1997. 180p. Tese (Doutorado em Genética e Melhoramento de Plantas)-Universidade Federal de Lavras, Lavras, 1997.

MATOS, J.W. de. Análise crítica do programa de melhoramento genético do feijoeiro da UFLA no período de 1974 a 2004. 2005. 116p. Tese (Doutorado em Genética e Melhoramento de Plantas)-Universidade Federal de Lavras, Lavras, 2005.

MELO, L.C.; SANTOS, J.B. dos; FERREIRA, D.F. Mapeamento de QTLs para florescimento do feijoeiro com marcadores RAPD em diferentes ambientes. Ciência e Agrotecnologia, Lavras, v.26, n.4, p.768-779, jul./ago. 2002.

MSTAT-C. Microcomputer statistical program. Michigan: Michigam State University, 1983.

PEREIRA, H.S.; SANTOS, J.B. dos; ABREU, A. de F.B.; COUTO, K.R. Informações fenotípicas e marcadores microsatéllite de QTL na escolha de populações segregantes de feijoeiro. Pesquisa Agropecuária Brasileira, Brasília, v.42, p.707-713, 2007.

RAMALHO, M.A.P.; SANTOS, J.B. dos; PINTO, C.A.B.P. Genética na agropecuária. Lavras: UFLA, 2000. 472p.

RAMALHO, M.A.P.; SANTOS, J.B. dos; ZIMMERMANN, M.J. de O. Genética quantitativa em plantas autógamas: aplicações ao melhoramento do feijoeiro. Goiânia: UFG, 1993. 271p.

RODRIGUES, T.B. Efeito da seleção natural em alelos microssatélites (SSR) do feijoeiro e associação com QTLs de caracteres agronômicos. 2004. 90p.

Dissertação (Mestrado em Genética e Melhoramento de Plantas)-Universidade Federal de Lavras, Lavras, 2004.

SANTOS, M.F. Mapeamento de QTLs em testecrosses de milho com diferentes testadores e níveis de acidez do solo. 2008. 167p. Tese (Doutorado)-Escola Superior de Agricultura Luiz de Queiroz, Piracicaba, 2008.

SILVA, D.V.F. Seleção de linhagens de feijoeiro tipo rosinha resistentes à antracnose, à mancha angular $\mathrm{e}$ de boa cocção. 2007. 71p. Dissertação (Mestrado em Genética e Melhoramento de Plantas)-Universidade Federal de Lavras, Lavras, 2007.

SOUZA, E.A.; GERALDI, I.O.; RAMALHO, M.A.P. Alternativas experimentais na avaliação de famílias em programas de melhoramento genético do feijoeiro. Pesquisa Agropecuária Brasileira, Brasília, v.35, n.9, p.1765-1771, set. 2000.

TEIXEIRA, F.F. Mapeamento de QTLs para caracteres do feijoeiro por meio de microssatélites. 2004. 189p. Tese (Doutorado em Genética e Melhoramento de Plantas)-Universidade Federal de Lavras, Lavras, 2004.

TEIXEIRA, F.F.; SANTOS, J.B. dos; RAMALHO, M.A.P.; ABREU, A. de F.B.; GUIMARÃES, C.T.; OLIVEIRA, A.C. de. QTL mapping for angular leaf spot in common bean using microssatelite markers. Crop Breeding and Applied Biotechnology, Londrina, v.5, n.3, p.272-278, Sept. 2005.

VENCOVSKY, R.; BARRIGA, P. Genética biométrica no fitomelhoramento. Ribeirão Preto: Sociedade Brasileira de Genética, 1992. 486p.

VENCOVSKY, R.; RAMALHO, M.A.P. Contribuições do melhoramento genético de plantas no Brasil. In: PATERNIANI, E. Agricultura brasileira e pesquisa agropecuária. Brasília: Embrapa Comunicação para Transferência de Tecnologia, 2000. p.57-89. 